\title{
ANALISIS KEUNTUNGAN USAHA PUPUK ORGANIK DI PERUSAHAN CV. ARGONIAGA MANDIRI KECAMATAN BINTAUNA
}

\author{
Rivaldi Lantapa*, M.A.V. Manese**, E. Wantasen** dan F.N.S. Oroh** \\ Fakultas Peternakan Universitas Sam Ratulangi, Manado,95115
}

\begin{abstract}
ABSTRAK
Tujuan dari penelitian ini adalah mengetahui berapabesar keuntungan yang diperoleh per tahun. Penelitian di lakukan pada CV Agroniaga Mandiri sebagai satu satunya perusahaan yang memproduksi pupuk organik di Kecamatan Bintauna Kabupaten Bolaang Mongondow Utara. Data yang dikumpulkan terdiri atas data primer dan data sekunder. Data primer berupa hasil wawancara yang dikumpulkan dengan alat bantu berupa kuesioner. Sedangkan data sekunder berupadata yang diperoleh dari instansi pemerintah yang terkait dengan penelitian ini yaitu dinas pertanian dan peternakan Kabupaten Bolaang Mongondow Utara. Data yang diperoleh dianalisis dengan mengunakan metode fungsi keuntungan. Hasil penelitian menunjukan bahwa jumlah biaya produksi,penerimaan dan keuntungan usaha pupuk organik CV Agroniaga Mandiri Kecamatan Bintauna Kabupaten Bolaang Mongondow Utara masing-masing sebesar Rp. 259.294.100 / tahun, Rp.405.000.000 / tahun, Rp.145.705.900 / tahun.
\end{abstract}

Kata Kunci: $\begin{aligned} & \text { Keuntungan, Pupuk } \\ & \text { organik }\end{aligned}$

\section{ABSTRACT}

PROFIT ANALYSIS OF ORGANIC FERTILIZER BUSINESS IN CV AGRONIAGA MANDIRI SUBDISTRICT BINTAUNA. The purpose of this study was to determine the company profits per year. This research was done at CV Agroniaga Mandiri as the only

\footnotetext{
*Alumni Fakultas Peternakan

**Jurusan Sosial Ekonomi
}

company that produces organic fertilizer in the Bintauna Sub-district, North Bolaang Mongondow Regency. Data collected consist of primary data and secondary data. The primary data were collected by interview with questions list or quetionnaire, while secondary data were obtained from government agency that related with this research such as Department of Agriculture and Animal Husbandry of North Bolaang Mongondow. Data were analyzed with profit function method. The results showed that the total cost of production, revenue and profit of organic fertilizer business that obtained by CV Agroniaga Mandiri sequentially Rp. 259, 294,100 / year, Rp.405,000,000/year and Rp.145,705,900/year.

\section{Key words: Profit, organic fertilizer}

\section{PENDAHULUAN}

Dinamika perkembangan ekonomi Indonesia dipengaruhi oleh dinamika perkembangan ekonomi global dan kawasan. Semakin tingginya jumlah penduduk berakibat pada sempitnya lapangan pekerjaan yang bisa menimbulkan pengangguran. Hal ini mendorong dilakukannya upaya untuk menciptakan lapangan kerja baru. Salah satu caranya yaitu dengan mengembangkan usaha berbasis pertanian yaitu agroindustri. Menurut data BPS 
(2011) laju pertumbuhan PDB sektor pertanian mencapai 4,1persen, pertumbuhan sektor pertanian menunjukan penyerapan tenagakerja sebesar 37,83 persen (43,03 juta orang), dengan total angkatan kerja 113,74 juta orang.

Peranan agroindustri dapat mendorong adanya pengembangan usaha untuk meningkatkan kesejahteraan petani pada khusunya dan masyarakat pada umumnya. Salah satu perusahan yang bergerak dalam bidang agroindustri di Sulawesi Utara adalah CV Agroniaga Mandiri. Perusahaaan ini berdiri pada tanggal 1 juni 2012. Perusahaan ini didirikan oleh Hamdan Datungsolang yang berlokasi di Desa Telaga Kecamatan Bintauna Kabupaten Bolaang Mongondow Utara. Jenis produk yang di hasilkan oleh perusahaan ini adalah pupuk cair dan pupuk padat. Usaha ini berawal dari memproduksi gas terlebih dahulu kemudian setelah 3 bulan perusahaan ini memperluas hasil produksinya berupa pupuk cair dan pupuk padat. Perusahaan ini memproduksi pupuk organik setiap 14 hari dan feses yang digunakan sebanyak 58,32 ton/tahun dari 24 ekor sapi. Pupuk padat yang diproduksi sebanyak 58,32 ton/tahun dan pupuk cair sebesar 8640 galon/tahun. Pupuk padat yang dihasilkan oleh perusahaan digunakan oleh para petani peternak di Kabupaten
Bolaangmongondow Utara. Usahatani dengan pupuk organik seperti pupuk padat dan pupuk cair ini lebih memberikan tambahan manfaat atau lebih menguntungkan dari pada usaha tani dibandingkan pupuk non organik (Astuti, 2006, Masarirambi et al 2010, Kalay dan Wijayanti , 2011, Afrizal dkk, 2014).

Penelitian Hermawati (2006) menunjukan bahwa pupuk organik yang di konsumsi oleh kelompok tani di desa pandanreja kota batu memberi pendapatan yang lebih tinggi dibandingkan pupuk anorganik. Hal ini berarti bahwa produsen yang memproduksi pupuk organik memiliki potensi untuk mengembangkan usahanya karena tingginya permintaan pasar. CV Agroniaga Mandiri sebagai satu-satunya produen pupuk organik di Kecamatan Bintauna yang sudah memproduksi dan menjual pupuk organic sejak tahun 2012. Namun demikian bagaimana struktur biaya dan keuntungan usaha tersebut masih belum diketahui sehingga penelitian ini penting untuk dilakukan.

\section{METODE PENELITIAN}

Penelitian ini dilaksanakan di Kecamatan Bintauna Kabupaten Bolaang Mongondow Utara mulai Februari 2015 Mei 2015. Penelitian akan dilaksanakan di 
CV Agroniaga Mandiri Kabupaten

Bolaangmongondow Utara. Penelitian ini menggunakan metode survei dengan pendekatan studi kasus pada CV Agronoaga Mandiri. Jenis data yang dikumpulkan dalam penelitian ini adalah data sekunder dan data primer. Data sekunder diperoleh dari instansi pemerintah seperti Dinas Pertanian dan Peternakan Kabupaten Bolaang mongondow Utara, BP4K Kabupaten Bolmut, BPS Kabupaten Bolmut, sedangkan data primer diperoleh dari hasil wawancara dengan teknisi dan direktur perusahaan dengan berpedoman pada daftar pertanyaan yang disediakan. Data primer antara lain berupa produksi pupuk, tenaga kerja dan bahan baku pupuk, harga output dan input, penerimaan biaya produksi pupuk dan keuntungan perusahan dari usaha pupuk organik.

\section{HASIL DAN PEMBAHASAN}

Berdasarkan hasil penelitian keuntungan yang diperoleh dari produksi pupuk organik selama satu tahun adalah 43,200kg pupuk padat dan pupuk cair
8640 galon. Biaya produksi penerimaan dan keuntungan usaha pupuk organik oleh CV Agroniaga Mandiri dapat dilihat pada table 1. Data pada table 1 mnyatakan bahwa biaya yang digunakan dalam produksi pupuk organik terdiri atas biaya tetap dan biaya variable. Biaya tetap berjumlah Rp.154.345.000/tahun yang antara lain berupa biaya gudang, rumput, mesin-mesin, digester, peralatan kandang, gaji pegawai, dan penyusutan peralatan.

Biaya variabel berjumlah Rp.104.949.100/tahun yang antara lain berupa upah pekerja harian, obat-obatan, pakan, mikobra, listrik, air dan lainnya. Tingkat keuntungan usaha sebesar Rp. 145.705.900/tahun. Hasil penelitian sejalan dengan Rianty Isaskar ( 2011 ) bahwa keuntungan usaha pupuk organik di Kecamatan Pandaan Kabupaten Pasuruan sebesar Rp. 218.188.000/ tahun.

Tabel 1. Struktur Biaya Penelitian dan Keuntungan Usaha Pupuk Organik CV. Agroniaga Mandiri. 


\begin{tabular}{|l|l|l|}
\hline No & Uraian & Jumlah (Rp) \\
\hline 1 & Biaya produksi/tahun & Rp. 154.354 .000 \\
$-\quad$ Biaya Tetap & Rp 104.949.100 \\
& $-\quad$ Biaya Variabel & Rp. 145.800 .000 \\
\hline 2 & Penerimaan Total & Rp. 259.200.000 \\
\hline 3 & Keuntungan & Rp. 145.705 .900 \\
\hline
\end{tabular}

Sumber: Data diolah 2015

\section{KESIMPULAN}

Dari hasil penelitian dan analisis diatas dapat disimpulkan bahwa CV Agroniaga Mandiri yang terletak di Kabupaten bolaang Mongondow Utara Kecamatan Bintauna mendapatkan total keuntungan sebesar Rp.145.705.900/tahun dari hasil penjualan pupuk organik padat dan cair.

\section{DAFTAR PUSTAKA}

Astuti, D.L 2006, Analisis Usaha Tani Padi Dengan Pupuk Organik Di Kabupaten Purworejo, Skripsi, Fakultas Pertanian. UNS Surakarta.

Afrizal.Z., Yuniar dan A Saleh. 2014. Analisis Kelayakan Pembangunan

Usaha Pupuk Organik di Provinsi Lampung. Reka Integra No 4
Afrizal.Z., Yuniar dan A Saleh. 2014. Analisis Kelayakan Pembangunan Usaha Pupuk Organik di Provinsi Lampung. Reka Integra No 4 (1) :196-205

BPS , 2011. Pertanian,Penganguran, dan Kemiskinan. Statistik Indonesia. Jakarta

Hermawati. 2006. Studi penggunaan Pupuk Organik Pada Kelompok Tani Musyawarah Tani I di Desa Pandanrejo Kecamatan Bumuaji Kota Batu.Skripsi. FP-UB. Malang

Kalay. A.M dan F.W. Wijayanti. 2011. Pengaruh biokelas dan pupuk kandang terhadap produksi kacang tanah. Agrinimal \Vol 1(1) : 28-32

Masarirambi. M.T., M.M.Hiawe, O.T. Oseni, and T.E Sibiya. 2010 . Effects of organicfertilizers on growth, yield, quality and sensory evaluation of red lettuce (Lactuca sativa L.) 'Veneza Roxa. Agric. Bio.J.N.Am 1(6): 13191324 
Riyanti, I. 2011. Analisis Keuntungan Pembuatan Pupuk Organik (Studi. KasusDi Koperasi Agung Jaya Kec. Pandaan, Kab. Pasuruan)

Wijayanti.I.K. 2011. Upaya meningkatkan pendapatan petani melalui pendampingan penerapan IPTEKS peningkatan produktivitas padi berbasis organic. Aplikasi Ipteks Ngayah 